\title{
Formação inicial de professores de Ciências da Natureza: relatos de uma prática docente diferenciada
}

\author{
Initial formation of teachers of Nature Sciences: reports of a \\ differentiated teaching practice
}

\author{
Cadidja Coutinho (cadidjabio@gmail.com) \\ Prof. Adjunta pela Universidade Federal do Pampa - UNIPAMPA Campus Dom Pedrito \\ Ana Carolina Gomes Miranda (miranda.acg@gmail.com) \\ Prof. Adjunta pela Universidade Federal do Pampa - UNIPAMPA Campus Dom Pedrito
}

\begin{abstract}
Resumo: $\mathrm{O}$ presente estudo apresenta um relato de experiência relacionado à formação inicial no curso de Ciências da Natureza Licenciatura da Universidade Federal do Pampa, campus Dom Pedrito, RS, cujo principal objetivo é socializar e apontar as possíveis contribuições referentes à utilização de diferentes materiais didáticos para o ensino das Ciências da Natureza, a partir das vivências no componente curricular obrigatório "Práticas Pedagógicas: Materiais Didáticos". Para isso, organizou-se a disciplina em seis módulos: jogos didáticos, modelo didático, experimentação, simulação, tecnologias educacionais e análise de livros didáticos, dos quais elencaram-se objetivos de aprendizagem a cada um desses módulos, isto é, objetivo conceitual, objetivo procedimental e objetivo atitudinal. Observou-se que os relatos apresentados demonstram possibilidades didáticas que podem contribuir com a inovação pedagógica na formação docente, incitar questionamentos, desenvolver a capacidade de reflexão, criticidade e investigação.
\end{abstract}

Palavras-chave: Formação inicial; Ensino de Ciências da Natureza; Estratégias de ensino.

\begin{abstract}
The present study presents an experience report related to initial training in the course of Nature Sciences Degree of the Federal University of Pampa, Campus Dom Pedrito, RS, whose main objective is to socialize and point out the possible contributions regarding the use of different didactic materials for the teaching of the Sciences of Nature, from the experiences in the compulsory curricular component "Pedagogical Practices: Didactic Materials". For this, the discipline was organized in six modules: didactic games, didactic model, experimentation, simulation, educational technologies and analysis of didactic books, from which learning objectives were attached to each of these modules, that is, conceptual objective, objective and attitudinal objective. Was observed that the presented reports demonstrate didactic possibilities that can contribute with the pedagogical innovation in the teacher formation, to incite questions, to develop the capacity of reflection, criticality and investigation.
\end{abstract}

Keywords: Initial training; Teaching of Natural Sciences; Teaching strategies. 


\section{AS INTERFACES ENTRE FORMAÇÃO INICIAL DOCENTE E CIÊNCIAS DA NATUREZA}

Atualmente existe o desafio em promover a melhoria do sistema educacional brasileiro, o que geralmente está vinculado a formação inicial de professores. É necessário criar espaços formativos para que o futuro docente possa repensar e refletir sobre aspectos relacionados com os processos de ensino e de aprendizagem, visando a transformação pedagógica (NÓVOA, 2016).

Muitas vezes, o ensino das Ciências, favorece apenas o estudo de fatos isolados e neutros, com a reprodução reduzida de "verdades científicas", em uma perspectiva de ensino passiva e transmissiva, o que pouco contribui para a formação da criticidade e de sujeitos que consigam interpretar e intervir na realidade em que vivem.

É necessário que os espaços formativos de professores das Ciências incitem reflexões profundas sobre conteúdos abordados e escolhas de estratégias de ensino que visem despertar o interesse dos alunos para os conhecimentos das Ciências. Esses aspectos corroboram com Brabo e Ribeiro (2015) ao afirmarem a necessidade do professor deixar de ser um mero transmissor de conhecimentos e exercer o papel de mediador, reconhecendo seus alunos como construtores de seus saberes.

Sabe-se que ainda hoje, tradicionalmente, os cursos de licenciatura têm valorizado o saber científico, com estreita dissociação da prática, o que pode implicar insegurança na docência. Em relação a isso, Tardif (2010, p. 242) enfatiza:

\footnotetext{
O que é preciso não é exatamente esvaziar a lógica disciplinar dos programas de formação para o ensino, mas pelo menos abrir um espaço maior para uma lógica de formação profissional que reconheça os alunos como sujeitos do conhecimento e não simplesmente como espíritos virgens aos quais nos limitamos a fornecer conhecimentos disciplinares e informações procedimentais, sem realizar um trabalho profundo relativo às crenças e expectativas cognitivas, sociais e afetivas através das quais os futuros professores recebem e processam estes conhecimentos e informações.
}

Diante disso, é necessário que os componentes curriculares dos cursos de licenciatura criem espaços para que o acadêmico desenvolva formas diferenciadas e inovadoras para abordar os conteúdos em sala de aula, neste estudo relacionados às Ciências da Natureza (Química, Física e Biologia) . 
Para Moraes e Mancuso (2014), a formação docente deve ser crítica, vinculada ao contexto de trabalho e baseada numa perspectiva do ensino como prática reflexiva, utilizando a investigação para compreender a educação como prática social concreta. $\mathrm{O}$ autor afirma que as tarefas docentes contêm múltiplos aspectos, e desta forma o dia a dia de um professor é permeado de situações, intenções e problematizações em torno de atividades de ensino, podendo produzir um cenário de tentativas de renovação das estratégias metodológicas, para a construção de um modelo didático inovador.

É necessário que os cursos de formação inicial para o ensino de Ciências da Natureza incentivem reflexões teóricas e práticas, oportunizando aos futuros professores o conhecimento sobre novas estratégias metodológicas, em contrapartida aos métodos tradicionais, dando lugar para atividades práticas diferenciadas, com vistas à aprendizagens mais significativas e duradouras.

A escolha de recursos didáticos e de estratégias para mediação do ensino é tão importante quanto selecionar os conteúdos específicos das Ciências. Os documentos oficiais da educação brasileira, como exemplo, as Orientações Curriculares para o Ensino Médio (OCEM) (BRASIL, 2006) ressaltam que a escolha adequada dos métodos e ou estratégias contribui significativamente para que os estudantes se apropriem dos conceitos científicos abordados. A Base Nacional Comum Curricular (BNCC) também indica a emergência por novos modelos na produção de materiais didáticos a fim de contemplar o estudo de características locais e regionais da sociedade, da cultura, da economia e da comunidade escolar (BRASIL, 2010).

Sendo assim, uma formação docente dentro dos aspectos supracitadas, pode contribuir para mudanças na escola, no trabalho e nas ações didáticas, favorecendo novas perspectivas sobre currículo, profissionalização e aspectos sociais e históricos do futuro ambiente de trabalho.

Diante disso, com base em nossas reflexões e nos referenciais contemporâneos da área do ensino de Ciências, acreditamos ser possível formar professores que possam impactar a educação básica brasileira de forma positiva, por meio da construção de uma prática pedagógica diferenciada, pautadas na interdisciplinaridade, contextualização e utilização de metodologias exitosas para o ensino das Ciências. Assim sendo, o principal 
objetivo deste trabalho é socializar e apontar as possíveis contribuições referentes à utilização de diferentes materiais didáticos para o ensino das Ciências da Natureza, a partir das vivências no componente curricular obrigatório "Práticas Pedagógicas: Materiais Didáticos" do curso de Ciências da Natureza Licenciatura da Universidade Federal do Pampa.

\section{PERCURSO METODOLÓGICO}

Considerando que a formação docente num curso superior de licenciatura requer a integração entre aspectos teóricos e experiências práticas para consolidação do perfil do egresso, as informações contidas nos componentes curriculares, em especial os relacionados às Práticas Pedagógicas do curso, podem delinear significativas reflexões para o processo formativo. Para tanto, torna-se necessário analisar o percurso das disciplinas, ou seja, identificar as contribuições das ações realizadas para constituir um corpus de conhecimentos relevantes.

Para o delineamento metodológico deste trabalho o propósito do nosso interesse foi o componente curricular obrigatório "Práticas Pedagógicas: Materiais Didáticos" do curso de Ciências da Natureza Licenciatura, com carga horária total de 60 horas, e com objetivo principal de analisar e refletir os materiais didático-pedagógicos para o ensino de Ciências.

Este trabalho, classifica-se como um Estudo de caso, que segundo Gil (2010, p. 58) se caracteriza " [...] pelo estudo profundo e exaustivo de um ou de poucos objetos, de maneira a permitir o seu conhecimento amplo e detalhado [...]”. As premissas do Estudo de caso permitem explorar diferentes instrumentos de pesquisa para análise e discussão dos resultados, neste caso, as diferentes propostas pedagógicas atribuídas ao componente curricular alvo da pesquisa.

O conteúdo programático da disciplina em estudo foi organizado em módulos (Quadro 1) elencando-se objetivos de aprendizagem a cada um dos módulos, isto é, objetivo conceitual (fundamentação teórica - termos, conceitos e conhecimentos científicos fundamentais), objetivo procedimental (elaboração de produtos educacionais 
- organização prática de materiais, processos e conceitos) e objetivo atitudinal (aplicação dos produtos - intervenção e reflexão da prática).

Quadro 1 - Distribuição dos módulos de trabalho e seus respectivos objetivos de aprendizagem.

\begin{tabular}{|c|c|c|c|}
\hline \multirow{2}{*}{ MÓDULOS } & \multicolumn{3}{|c|}{ OBJETIVO DE APRENDIZAGEM } \\
\hline & CONCEITUAL & PROCEDIMENTAL & ATITUDINAL \\
\hline Jogo didático & $\begin{array}{c}\text { Aliar conceitos teóricos à } \\
\text { ludicidade; } \\
\text { Aprimorar as relações entre } \\
\text { professor - } \\
\text { aluno - conhecimento; } \\
\text { Motivar a aprendizagem dos } \\
\text { conceitos; }\end{array}$ & $\begin{array}{c}\text { Elaborar um jogo } \\
\text { didático para o ensino } \\
\text { de Ciências da } \\
\text { Natureza; }\end{array}$ & $\begin{array}{c}\text { Intervir através do } \\
\text { exemplo elaborado num } \\
\text { espaço real (sala de } \\
\text { aula); }\end{array}$ \\
\hline Modelo didático & $\begin{array}{l}\text { Aproximar o conteúdo com uma } \\
\text { realidade; } \\
\text { Abordar o conteúdo por meio } \\
\text { dos três níveis de representação } \\
\text { da matéria: macroscópico, } \\
\text { microscópico e simbólico; }\end{array}$ & $\begin{array}{c}\text { Reconhecer modelos } \\
\text { didáticos para o ensino } \\
\text { de Ciências da } \\
\text { Natureza; }\end{array}$ & $\begin{array}{l}\text { Intervir através do } \\
\text { exemplo elaborado num } \\
\text { espaço real (sala de } \\
\text { aula); }\end{array}$ \\
\hline Experim & $\begin{array}{c}\text { Observar e analisar as } \\
\text { contribuições da experimentação } \\
\text { para o ensino de Ciências; }\end{array}$ & $\begin{array}{c}\text { Elaborar um } \\
\text { experimento para o } \\
\text { ensino de Ciências da } \\
\text { Natureza; }\end{array}$ & $\begin{array}{c}\text { Intervir através do } \\
\text { exemplo elaborado num } \\
\text { espaço real (sala de } \\
\text { aula); }\end{array}$ \\
\hline Simulação & $\begin{array}{l}\text { Facilitar a compreensão de } \\
\text { conceitos; } \\
\text { Permitir identificar e manipular } \\
\text { diferentes fatores do um } \\
\text { processo através de simuladores; }\end{array}$ & $\begin{array}{l}\text { Elaborar uma sequência } \\
\text { didática com uso de } \\
\text { simulação para o ensino } \\
\text { de Ciências da } \\
\text { Natureza; } \\
\end{array}$ & $\begin{array}{l}\text { Intervir através do } \\
\text { exemplo elaborado num } \\
\text { espaço real (sala de } \\
\text { aula); }\end{array}$ \\
\hline $\begin{array}{l}\text { Tecnologias } \\
\text { educacionais }\end{array}$ & $\begin{array}{c}\text { Reconhecer as tecnologias } \\
\text { educacionais disponíveis para o } \\
\text { ensino; } \\
\text { Delimitar benefícios e limites do } \\
\text { uso das tecnologias; }\end{array}$ & $\begin{array}{c}\text { Elaborar uma } \\
\text { sequência didática com } \\
\text { uso de uma tecnologia } \\
\text { para o ensino de } \\
\text { Ciências da Natureza; }\end{array}$ & $\begin{array}{l}\text { Intervir através do } \\
\text { exemplo elaborado num } \\
\text { espaço real (sala de } \\
\text { aula); }\end{array}$ \\
\hline $\begin{array}{c}\text { Análise de livro } \\
\text { didático }\end{array}$ & $\begin{array}{c}\text { Identificar o potencial educativo } \\
\text { do livro didático e suas } \\
\text { carências; }\end{array}$ & $\begin{array}{c}\text { Elaborar categorias e } \\
\text { analisar um exemplar } \\
\text { de cada área das } \\
\text { Ciências da Natureza; }\end{array}$ & $\begin{array}{c}\text { Intervir através do } \\
\text { exemplo elaborado num } \\
\text { espaço real (sala de } \\
\text { aula); }\end{array}$ \\
\hline
\end{tabular}

Para iniciar as intervenções buscou-se instigar a discussão sobre as interfaces entre recurso didático, material didático e ferramentas didáticas. Salienta-se também que a produção de cada módulo foi realizada em grupos de 4 a 5 alunos matriculados e assíduos na disciplina, e ao final de cada etapa havia a socialização das ideias propostas na turma. 
Para análise dos dados buscou-se aporte nas orientações de Bardin (2009) para análise do conteúdo, organizando as informações de caráter qualitativo. Além disso, para facilitar a compreensão dos dados encontrados utilizou-se de figuras e de descrição numérica dos informes.

\section{APRESENTAÇÃO DOS RESULTADOS E DISCUSSÃO}

Os dados apresentados neste estudo são resultantes da organização metodológica do componente curricular obrigatório "Práticas Pedagógicas: Materiais Didáticos" do curso de Ciências da Natureza Licenciatura, da Universidade Federal do Pampa. Cursaram o componente 16 alunos, 15 do sexo feminino e 1 do sexo masculino.

Para atender os objetivos propostos para o componente supracitado organizou-se módulos de trabalho que perpassaram as principais estratégias didáticas para o ensino de Ciências da Natureza, elencadas pelas professoras regentes da disciplina. Cada módulo possuía objetivos de aprendizagem, ou seja, objetivo conceitual, objetivo procedimental e objetivo atitudinal.

Para o módulo 1 optou-se pela elaboração de jogo didático, um material educativo para atrelar os conceitos da área de Ciências da Natureza de forma lúdica e fomentar o processo de aprendizagem. Os critérios do jogo deveriam ser estabelecidos pelos acadêmicos, assim como o público-alvo e os conceitos abordados na proposta. Considerou-se também a viabilidade de aplicação do jogo e sua jogabilidade. Em geral os jogos confeccionados pelos acadêmicos foram adaptações de jogos pré-existentes, a saber: jogo da memória, twister, jogo de cartas com perguntas e respostas. Como afirma Cunha (2012) o jogo didático permite a apropriação de conceitos, como os conteúdos associados às Ciências da Natureza, de forma lúdica, educativa e baseada em regras.

Assim como na proposta do módulo 1, é preciso destacar que a ludicidade deve apresentar uma intencionalidade didática. Um jogo didático exige planejamento prévio do docente, com objetivos e metas para otimização do processo de ensino e de aprendizagem. Para Almeida e colaboradores (2016, p.3), "não é apenas levar o discente ter mais facilidade de memorização dos conteúdos abordados, mas sim, induzir a reflexão, o raciocínio e a construção do conhecimento". 
No segundo módulo buscou-se identificar modelos didáticos e suas possibilidades para o ensino de Ciências da Natureza, considerando que a modelização pode auxiliar na reflexão, no debate e na participação ativa dos alunos num contexto de ensino (DUSSO, 2012). A execução da tarefa exigiu dos discentes a visita em escolas públicas municipais e estaduais da cidade para observação de modelos didáticos disponíveis nas instituições. A partir de registros fotográficos (por exemplo, figura 1), a socialização das informações encontradas deveria apresentar as possíveis relações do modelo com os temas da área e um exemplo de planejamento pedagógico utilizando os mesmos.

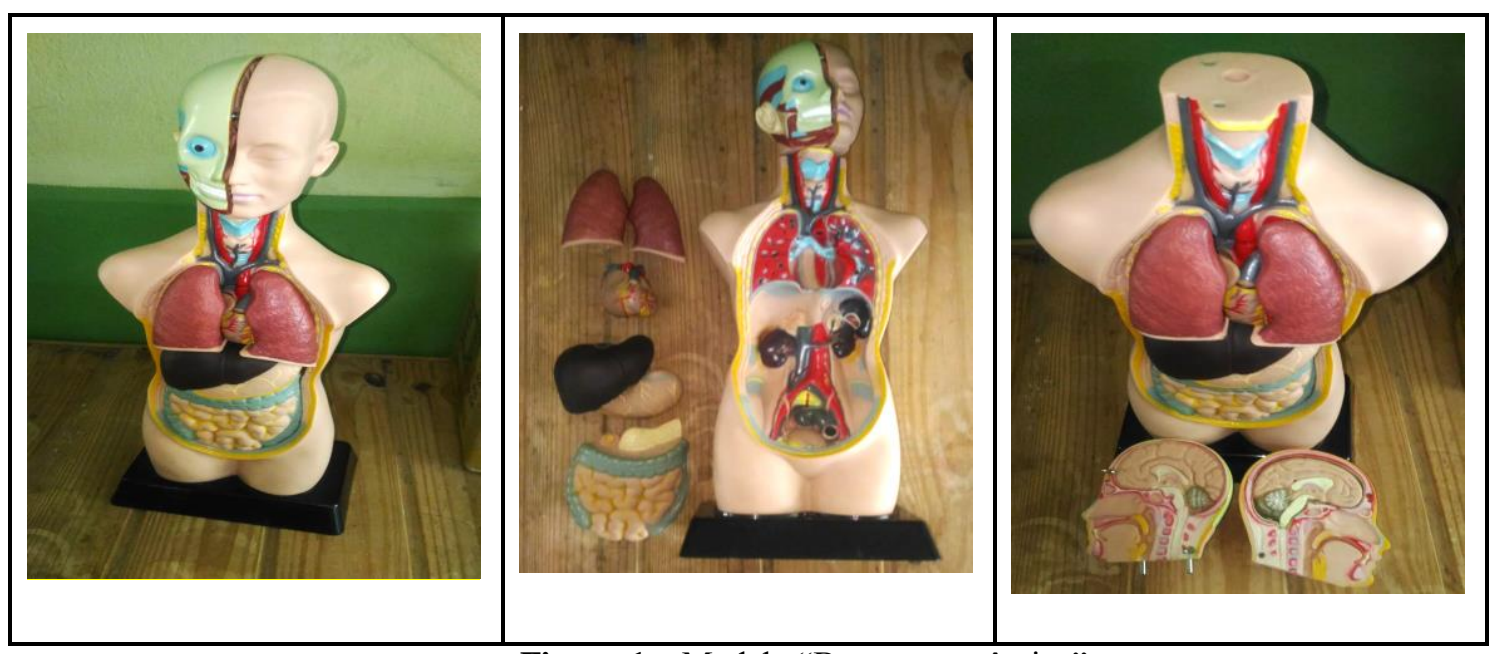

Figura 1 - Modelo "Boneco anatômico".

Fonte: Autores, 2019.

Já no módulo 3 utilizou-se da infraestrutura da universidade para realização de práticas experimentais de química e biologia. Precedente as práticas, os discentes deveriam realizar uma busca sobre o conceito e importância da experimentação para as Ciências da Natureza. Após o embasamento teórico, os mesmos foram convidados a participar de uma prática experimental de microscopia, com observação de mucosa bucal e identificação de célula animal. Em seguida, realizou-se uma atividade no laboratório de química com o objetivo de aprimorar habilidades manipulativas, estimular a criatividade, bem como aprender a analisar dados e propor hipóteses para os fenômenos.

As aulas práticas propostas tinham como intuito aproximar o aluno ao ambiente laboratorial, relembrar regras e procedimentos necessários para manuseio de equipamentos, vidrarias e demais materiais de laboratório. Da mesma forma, mostrar possibilidade para uso da experimentação na educação básica, considerando a realidade 
de cada instituição e as necessidades de adaptação de materiais, espaço físico e mesmo dos roteiros de aulas.

Diante disso, a experimentação pode ser entendida como uma intervenção que possibilita relacionar os conceitos teóricos com o dia a dia do aluno, evidenciando a relação da Ciência com a realidade. Além disso, pode auxiliar os estudantes no desenvolvimento de sua capacidade de investigar, questionar e argumentar sobre teorias e fórmulas. Ainda, segundo Galiazzi e Gonçalves (2004), realizar um experimento seguido de discussão para interpretação de resultados é uma atividade extremamente rica em termos de aprendizagem. Desta forma, torna-se importante o planejamento de atividades experimentais que coloquem o estudante frente a situações problema, pois além de estimulá-lo a levantar hipóteses e questionamentos, proporciona também, a construção do próprio conhecimento.

Os dois módulos seguintes buscaram aporte em tecnologias educacionais, reconhecendo o uso de Tecnologias da Informação e Comunicação (TIC) aplicadas à educação. Num primeiro momento fez-se o uso de simuladores para motivar a aprendizagem em Ciências da Natureza, ilustrando processos e métodos científicos de forma dinâmica e permitindo a manipulação de fatores em uma realidade virtual.

Na sequência incitou-se o uso de tecnologias educacionais requisitando aos acadêmicos a elaboração de planejamentos didáticos com uso de pelo menos uma TIC. Os roteiros elaborados contemplaram os conceitos-chave das Ciências da Natureza com uma abordagem inovadora, utilizando de jogos digitais, simuladores, histórias em quadrinhos e mapas conceituais online para problematizar e/ou organizar o conteúdo.

Estabelecer a inserção das TIC no ensino de Ciências pode representar uma nova estratégia pedagógica, atendendo as necessidades de uma sociedade que prioriza a comunicação como processo de mediação educacional. Esse processo caracteriza-se como uma formação audiovisual, comunitária e de interação que pode interferir nas formas tradicionais de ensino (CARVALHO, 2010). Além disso, estudos mostram que as TIC têm maior impacto no desenvolvimento dos alunos quando são incluídas como parte integrante das experiências vivenciadas em sala de aula (CAERÃO; FUSSINGER; 
FERRARI, 2017). Informações estas que corroboram com a intencionalidade da proposta do módulo 5.

Por fim, propôs-se a análise de livros didáticos de Ciências para ensino fundamental; de química, física e/ou biologia para ensino médio. Os acadêmicos deveriam buscar exemplos de análise em publicações da área e estabelecer os critérios a serem adotados para verificar o livro escolhido. Destaca-se que a atividade representou um exercício e os dados encontrados não permitem generalização ou mesmo divulgação, uma vez que cada grupo observou apenas um exemplar e um conteúdo presente no livro escolhido.

Tal proposta se justifica pela influência e papel desempenhado pelo livro didático no ambiente escolar. No estudo de qualquer área, em específico da Ciências da Natureza, o livro didático ainda é uma referência importante no processo de ensino e aprendizagem. Embora o aluno e o professor possam contar com outros recursos para obter informações sobre a ciência, o livro didático continua tendo um papel fundamental na obtenção de conhecimentos científicos. Melzer (2008) afirma que o livro didático se apresenta como um importante instrumento, não só de apoio, mas como base teórico-metodológico para os professores e de base teórico-científica para os estudantes.

Diante dos pressupostos apresentados, é preciso salientar que o intuito deste trabalho compõe o escopo de iniciativas para formação de professores. Se aproxima das orientações de Shulman (2005), quando apresenta objetivos de aprendizagem para as ações de cada módulo (objetivo conceitual, objetivo procedimental e objetivo atitudinal). Segundo o autor, há sempre uma síntese de três aprendizagens na constituição do profissional docente, uma aprendizagem cognitiva, na qual se aprende a pensar como um profissional; uma aprendizagem prática, na qual se aprende a agir como um profissional; e uma aprendizagem moral, na qual se aprende a pensar e agir de maneira responsável e ética.

\section{CONSIDERAÇÕES FINAIS}

O presente trabalho emergiu a partir dos desafios impostos à qualidade da educação básica, o que está diretamente relacionado com a formação inicial de 
professores. Diante disso, faz-se necessário refletir sobre as ações que possam contribuir com a sua melhoria, tanto para o alcance dos objetivos educacionais e estratégias de ensino, bem como para atender às necessidades e aos interesses da comunidade na qual a escola está inserida. Estratégia de ensino é um elemento curricular básico e precisa ser constantemente repensada, buscando um significado transformador para ela.

Conscientes que somos responsáveis pela formação de professores que atuarão na educação básica, buscamos inserir nesse processo novas possibilidades formativas, com vistas ao fortalecimento da indissociabilidade teoria/prática.

Neste sentido, as proposições feitas para o componente de Práticas Pedagógicas foram descritas neste trabalho de forma a inspirar outros profissionais da área para importância de conhecer e diversificar os materiais, recursos e ferramentas didáticas no processo de ensino e de aprendizagem. Evitando generalizações, consideramos pertinente reconhecer a gama de materiais e metodologias hoje disponíveis, mas além disso, a necessidade dos licenciados de se apropriar de tais propostas não esquecendo da responsabilidade docente e da base conceitual.

Os relatos apresentados demonstram possibilidades didáticas que podem favorecer a inovação pedagógica na formação docente, exercitar os questionamentos, desenvolver a capacidade de reflexão, criticidade e investigação.

Numa perspectiva futura, pode-se utilizar outros materiais didáticos, em outros componentes curriculares, analisando e descrevendo as potencialidades dos mesmos para a formação de professores, seja inicial ou continuada.

\section{REFERENCIAS}

ALMEIDA, C. M. M de. PROCHNOW, T. R. LOPES, P. T. C. O uso do lúdico no ensino de ciências: jogo didático sobre a química atmosférica. Universidad Distrital Francisco José de Caldas. Revista Góndola: Enseñanza y aprendizaje de las ciências. Barcelona, v. 11, n. 2, 2016.

BRABO, J. N. C. ; RIBEIRO, Elinete O R . Metodologia do Ensino de Ciências: Concepções e Práticas. Belém: Editora da UFPA, 2015.

BRASIL. Ciências da Natureza, Matemática e suas Tecnologias. Parâmetros Curriculares Nacionais - Ensino Médio: Orientações Educacionais Complementares aos parâmetros Curriculares Nacionais. Brasília: MEC/SEMTEC, 2006. 
Resolução No 4, de 13 de Julho de 2010. Define Diretrizes Curriculares Nacionais Gerais para a Educação Básica. Disponível em:

<http://portal.mec.gov.br/dmdocuments/rceb004_10.pdf.> Acesso em 20 jan. 2019.

CAERÃO, I. S.; FUSSINGER, L.; FERRARI, R. F. O uso da tecnologia e sua relação com a neuroeducação no contexto universitário. In: A pesquisa em educação e tecnologias: entre perguntas e respostas [recurso eletrônico] / Organizadoras: Elisabete Cerutti, Manoelle Silveira Duarte. - Frederico Westphalen : URI - Frederico Westph, 2017.

CARVALHO, K. B. Implicações das TICs na Educação. In: Resenha de Tese de Mestrado. Universidade de Estadual de Campinas. São Paulo. 2010.

CUNHA, M. C. da. Jogos no ensino de Química: Considerações teóricas para sua utilização em sala de aula. Química Nova na Escola. v. 34, n. 2, p. 92- 98, 2012.

DUSSO, L. O uso de modelos no ensino de Biologia. Campinas, 2012.

MORAES, R. MANCUSO, R. Educação em Ciências: produção de currículos e formação de professores. Ijuí: UNIJUÍ. 2014.

NÓVOA, A. Formação de professores e profissão docente. In. Os professores e a sua formação. 2a ed. Lisboa: Nova Enciclopédia, 2016.

TARDIF, M. Saberes Docentes e Formação Profissional. 7. ed. Petrópolis: Vozes, 2010. 